\title{
ANÁLISE DO LABORATÓRIO VIRTUAL DE APRENDIZAGEM LABHIDRA.COM APLICADO AO ENSINO DE HIDRÁULICA
}

\section{Análisis del Laboratorio Virtual de Aprendizaje Labhidra.com Aplicado a la Enseñanza de la Hidráulica}

\author{
Guilherme Augusto de Matheucci e Silva Teixeira ${ }^{1}$ \\ Ana Maria Beims Lopes ${ }^{2}$ \\ Juliana Cristina Faggion Bergmann ${ }^{3}$
}

\begin{abstract}
Resumo: Este trabalho tem como objetivo realizar uma análise pedagógica de um laboratório virtual de ensino de Engenharia utilizado como apoio a um experimento real de hidráulica, o LabHidra.com. O programa foi inovador na área hidráulica, pois buscou realizar a reprodução de experimentos reais associada a uma estrutura didática com imagens, explicações, esquemas e gráficos. Para realizar a análise, contemplamos uma análise ergonômica e pedagógica, utilizando o método de LORI e a Colmeia de Apps, com o objetivo de verificar as características gerais do programa em relação à sua estrutura e organização e também quanto ao conteúdo em relação ao potencial de ensino e aprendizagem. Como forma de aplicação ao ensino, avaliou-se possibilidades de uso do LabHidra.com pelo professor e pelo aluno. Isto é, idealizamos possíveis estratégias de aula pensando como o professor poderia inclui-lo de forma ativa no ensino. Constatou-se que o programa, em boa parte, aproveita-se de seus recursos visando a um diálogo com o aluno. As explicações didáticas, as instruções e a interatividade conferem ao LabHidra.com um caráter didático. Dessa forma, o aluno pode ter a autonomia de utilizar esse recurso em casa seguindo seu ritmo, como uma sala de aula invertida e obtendo o protagonismo. No entanto, vale ressaltar a importância da experimentação prática real e da sala de aula para promover a visualização concreta dos experimentos.
\end{abstract}

Palavras-chave: Recurso Didático Digital. Laboratório Virtual. Metodologias Ativas de Ensino.

\footnotetext{
${ }^{1}$ Graduação em Engenharia Sanitária e Ambiental pela Universidade Federal de Santa Catarina (UFSC) (2018), Mestrado em Engenharia Ambiental pela UFSC (2019) e doutorando do Programa de Pós-Graduação em Engenharia Ambiental pela UFSC. Orcid: https://orcid.org/0000-0002-2084-9015. E-mail: guilherme_amst@yahoo.com.br.

${ }^{2}$ Graduação em Engenharia Sanitária e Ambiental pela Universidade Federal de Santa Catarina (UFSC) (2017), Mestrado em Engenharia Ambiental pela UFSC (2020) e doutoranda do Programa de Pós-Graduação em Engenharia Ambiental pela UFSC. Orcid: https://orcid.org/0000-0002-8918-690X. E-mail: anamariabeims@gmail.com.

${ }^{3}$ Professora do Departamento de Metodologia de Ensino (MEN) da Universidade Federal de Santa Catarina (UFSC). Doutorado em Sciences du Langage pela Université Lumière (2009). Mestrado em Letras pela Universidade Federal do Paraná (UFPR) (2002). Orcid: https://orcid.org/0000-0002-0535-5279. E-mail: jcfbergmann@gmail.com.
} 
Resumen: Este trabajo tiene como objetivo realizar un análisis pedagógico de un laboratorio virtual de enseñanza de ingeniería, utilizado como soporte para un experimento de hidráulica real, el LabHidra.com. El programa fue innovador en el área hidráulica, ya que buscó reproducir experimentos reales asociados a una estructura didáctica, con imágenes, explicaciones, diagramas y gráficos. Para realizar el análisis de LabHidra.com, se contempló una evaluación ergonómica y pedagógica, usando el método LORI y Colmeia de Apps, con el fin de verificar las características generales del programa con relación a su estructura y organización, y también en cuanto al contenido, en lo que se refiere a la enseñanza y el aprendizaje. Como forma de aplicación a la docencia, se evaluaron las posibilidades de uso de LabHidra.com por parte del profesor y del alumno. Es decir, idealizamos posibles estrategias de lección, pensando en cómo el profesor podría incluirlo activamente en la docencia. Se constató que el programa, en gran medida, aprovecha sus recursos, apuntando al diálogo con el alumno. Las explicaciones didácticas, las instrucciones y la interactividad confieren a LabHidra.com un carácter didáctico. De esta manera, el alumno puede tener la autonomía para utilizar este recurso en casa, siguiendo su ritmo, como un aula invertida, ganando protagonismo. Sin embargo, cabe destacar la importancia de la clase práctica real y el aula, para promover la visualización concreta de los experimentos.

Palabras-clave: Recurso Didáctico Digital. Laboratorio Virtual. Metodologías Activas de Enseñanza.

\section{Introdução}

As mudanças no contexto social e político do mundo atual aumentaram os estudos em relação ao desenvolvimento educacional e ao papel da escola na construção do conhecimento (DE SOUZA; DE GODOY DALCOLLE, 2007). Nesse âmbito, tornaram-se emergentes as análises de instrumentos, materiais e processos de auxílio ao ensino conhecidos como recursos didáticos e pedagógicos (EITERER; MEDEIROS, 2010).

A adoção da tecnologia na educação, sobretudo, amplificou as pesquisas realizadas acerca de sua utilização em aula. Os recursos computacionais disponíveis possuem grande capacidade de acelerar o processo de ensino, garantir a interatividade e mediar o conhecimento entre professores e alunos (BORGES; TEIXEIRA; ACEDO, 2020).

No contexto da Engenharia, o uso de tecnologia nas disciplinas, muitas vezes, está voltado para programas de desenvolvimento de projetos (KANG et al., 2013) ou laboratórios virtuais (GAO et al., 2011). Os laboratórios ou experimentos virtuais usam a tecnologia como forma de transpor para o ambiente computacional situações práticas possíveis de serem encontradas no mercado de trabalho (YARBROUGH; GILBERT, 1999). Entretanto, são poucos os que se preocupam com as estruturas didáticas ou melhorias no potencial de ensino, e restringem-se a auxiliar atividades práticas profissionais. Assim, há uma carência no aproveitamento do uso de recursos midiáticos propiciado por um programa de computador.

A partir disso, este trabalho tem como objetivo realizar uma análise pedagógica de um laboratório virtual de ensino de Engenharia utilizado como apoio a um experimento real de hidráulica. O estudo tem como finalidade verificar suas potencialidades para a aprendizagem, além de discutir possibilidades no seu uso como metodologia ativa no processo de ensino. 
O objeto em questão é o LabHidra.com ${ }^{4}$. O programa foi inovador na área de hidráulica, pois buscou realizar a reprodução de experimentos reais associada a uma estrutura didática voltada para o ensino com o uso de imagens, explicações, esquemas e gráficos. Como apresenta autossuficiência em relação a maior parte dos conteúdos envolvidos, permite que o aluno amplie seus conhecimentos por si só e reproduza o experimento quantas vezes achar necessário. Assim, há uma mudança no protagonismo dando um caráter mais ativo ao estudante. Vale ressaltar que o programa não pretende substituir o papel do professor e nem extinguir os conteúdos em sala de aula. $\mathrm{O}$ objetivo é servir como complemento às práticas dando maior autonomia.

Assim, para fins deste trabalho o laboratório virtual foi analisado quanto à interface gráfica, ao conteúdo, à organização, aos feedbacks e aos recursos utilizados. Por fim, buscouse avaliar como poderia ser usado em sala e os efeitos pedagógicos de cada aplicação.

\section{Metodologias ativas de ensino}

O aumento no desinteresse dos alunos em relação às aulas demonstra a ineficiência dos métodos tradicionais de ensino, que se baseiam apenas em uma transmissão de informações (DOS SANTOS; SOARES, 2011). A utilização de recursos didáticos digitais é um ponto importante na adoção de novas metodologias de ensino. Correntes como as metodologias ativas crescem cada vez mais no meio acadêmico, verificando sua viabilidade para mudar os paradigmas do ensino atual.

Recursos didáticos ou pedagógicos podem ser definidos como objetos, instrumentos, materiais, processos, profissionais ou lugares com características educativas que visem a assegurar adaptação recíproca do conteúdo aos indivíduos que buscam conhecer (EITERER; MEDEIROS, 2010). Assim, devemos ampliar o significado do termo para além da materialidade de objetos físicos para abordar, também, ações e métodos. Isto é, todo e qualquer meio possível que contribua para a aprendizagem pode ser considerado um recurso pedagógico.

As metodologias ativas são estratégias de ensino que colocam o protagonismo da aprendizagem no aluno, sendo esse o centro da construção do próprio conhecimento. Dessa forma, o professor agiria como um mediador, um mentor para a aquisição dos conteúdos propiciando ao estudante atingir um patamar acima do que poderia alcançar sozinho (BACICH; MORAN, 2018).

O aprendizado de forma ativa envolve os princípios cognitivos do aluno de modo personalizado, em que ele precisa buscar, processar e refletir sobre os conteúdos avaliados (FERRARINI; SAHEB; TORRES, 2019). O docente, possivelmente uma pessoa mais experiente, busca avaliar a motivação de cada estudante e reorganizar o ambiente escolar para otimizar o processo (BACICH; MORAN, 2018). A sala de aula seria um espaço para a promoção de discussões em grupo, realização de atividades relacionadas aos conteúdos adquiridos e realização de contextualizações (LEUNG; WANG; CHAN, 2007).

$\mathrm{Na}$ adoção de metodologias ativas, há uma maior flexibilização na execução e aplicação das avaliações, permitindo ao aluno maior liberdade de escolha e sofrendo menos pressão psicológica (BERBEL, 2011). Entretanto, o estudante precisa sair de sua zona de conforto (BORGES; ALENCAR, 2014) e desenvolver habilidades como: "iniciativa, criatividade,

\footnotetext{
${ }^{4}$ O software foi desenvolvido no Programa de Pós-Graduação em Engenharia Ambiental da Universidade Federal de Santa Catarina (UFSC), registrado no Instituto Nacional de Propriedade Industrial (INPI) sob o processo No: BR512020000441-5. Está disponível apenas nas plataformas das disciplinas de hidráulica dos cursos de graduação de Engenharia Sanitária e Ambiental, Engenharia Civil e Engenharia de Produção Civil da UFSC.
} 
criticidade reflexiva, capacidade de autoavaliação, cooperação para se trabalhar em equipe, responsabilidade, ética e a sensibilidade na assistência" (MITRE et al., 2008).

Apesar de as metodologias ativas serem beneficiadas pelas tecnologias digitais, somente essas últimas não são suficientes para configurar o caráter ativo da aprendizagem. A estratégia, os papéis do aluno e do professor e a disposição e organização das disciplinas são fundamentais para esta composição (FERRARINI; SAHEB; TORRES, 2019). Seu desenvolvimento rompe os preceitos tradicionais de educação, pois o aluno passa a adquirir o conhecimento de diversas maneiras, sem deixar de ser guiado pelo professor. Isso o incentiva a desenvolver suas próprias habilidades focando em suas aptidões.

\section{Considerações sobre os laboratórios virtuais: conceito, uso, vantagens e enquadramento em relação às metodologias de ensino}

No contexto da aplicação prática em cursos de educação superior, e mesmo em escolas (GAO et al., 2011), os laboratórios físicos são um recurso pedagógico concebido normalmente para promover o ensino (EITERER; MEDEIROS, 2010). Eles permitem a aplicação de problemáticas e de experimentos reais aos alunos, melhorando seus processos cognitivos (NEUPAUER; DENNIS, 2010). No entanto, acabam por ser limitados tanto pelo espaço físico ao qual estão situados, quanto pelo tempo de aula. Além do que, as repetições não são viáveis e o acúmulo de pessoas pode atrapalhar o entendimento (NEDIC; MACHOTKA; NAFALSKI, 2003).

Como alternativa para compensar essas limitações, propõe-se o uso de recursos digitais no ensino com a utilização da tecnologia virtual para se aproximar do aluno (DOS SANTOS; NICOLETE; SILVA, 2017). Neste sentido, emergem os laboratórios virtuais para reproduzir e amplificar os experimentos práticos em um programa multimidiático de computador (YARBROUGH; GILBERT, 1999).

Os laboratórios virtuais permitem que cada aluno realize o experimento no seu próprio ritmo e repetindo-o quantas vezes forem necessárias, não estando limitado ao tempo e ao espaço de aula presencial (NEDIC; MACHOTKA; NAFALSKI, 2003). Esse componente o assemelha a uma sala de aula invertida, dando ao aluno a responsabilidade no aprendizado (FERRARINI; SAHEB; TORRES, 2019).

As vantagens vão além de superar as restrições do espaço e tempo porque permitem o uso de explicações didáticas, expansão dos experimentos físicos, dentre outros fatores. Entretanto, vale ressaltar que os experimentos em meio digital não devem ser vistos como substitutos dos laboratórios físicos, e sim como um complemento, unindo-se os benefícios de ambos os sistemas (NEDIC; MACHOTKA; NAFALSKI, 2003). Assim sendo, como qualquer outro recurso digital, o laboratório virtual deve ser considerado como potencializador do processo de ensino e aprendizagem (MACHADO, 2017).

Em cursos de Engenharia, a utilização de programas digitais está normalmente voltada ao uso de softwares profissionalizantes (KANG et al., 2013) e laboratórios virtuais, principalmente de circuitos eletrônicos e elétricos (HODGE; HINTON; LIGHTNER, 2001) e de máquinas hidráulicas (GAO et al., 2011).

Esses softwares, concebidos ou não com a finalidade de ensino, apesar de terem a possibilidade de melhorar o desempenho dos alunos na realização de testes e experimentações, ainda carecem de uma estética visual e didática adequada para otimizar os processos de aprendizagem. 
$\mathrm{Na}$ área de hidráulica, Chan et al. (2008) transpuseram um experimento real de hidráulico-mecânica através de um programa de modelagem 3D, que foi disponibilizado a alunos e professores através da internet com o objetivo de promover a pré-visualização do módulo antes de sua realização em uma aula de laboratório tradicional. Os autores sugeriram que somente esse fato já pode melhorar a qualidade de ensino e aprendizagem. Há instruções de manuseio, porém, ainda é necessária a presença de um professor ou guia para a explanação dos conteúdos.

Gao et al. (2011) também desenvolveram um laboratório virtual de mecanismos hidráulicos expondo os circuitos e a disposição de válvulas. O programa foi aplicado para um grupo de alunos randomicamente antes da realização de um experimento real existente. Após o uso, a maior parte dos comentários daqueles indicaram que o software contribuiu para um maior entendimento dos equipamentos físicos em si, facilitando sua manipulação posterior. Da mesma forma que Chan et al. (2008), o programa desenvolvido teve como principal objetivo a reprodução de um experimento real, mas tendo ainda como necessidade as instruções externas para a compreensão do assunto.

Os laboratórios virtuais podem ser acessíveis na internet para download ou mesmo se utilizar a rede em um processo colaborativo. Dessa forma, tal recurso contém características que podem enquadrá-lo tanto como um Objeto Virtual de Aprendizagem (OVA) quanto como um Ambiente Virtual de Aprendizagem (AVA).

O Objeto Virtual de Aprendizagem (OVA) é aquele que transmite a informação digital através de um combinado de suportes chamado multimídia, com linguagem hipermidiática onde diferentes linguagens se integram (GALLO; PINTO, 2010). Pode ser reutilizado dentro de várias atividades no processo de ensino e adaptar-se às necessidades de professor e aluno, compondo diversas estratégias metodológicas (SALVADOR et al., 2017).

Por sua vez, um Ambiente Virtual de Aprendizagem (AVA) reúne vários e diferentes tipos de OVAs em um contexto pedagógico comum. É capaz de armazenar, distribuir e gerenciar conteúdos de aprendizado através de ferramentas síncronas e assíncronas. Seu acesso pode se dar através de páginas online ou por meio de uma rede local (SALVADOR et al., 2017).

No que diz respeito ao caráter prático do laboratório virtual, ou seja, no momento em que é aplicado e reutilizado como um experimento digital, ele pode ser considerado um OVA. Todavia, ao analisá-lo como um espaço virtual contendo um conjunto de módulos se encaixa no conceito de AVA. Portanto, pela sua diversidade, se torna um gênero único e singular dentro da gama de recursos didáticos digitais.

Devido ao seu caráter próprio, pode ser usado para auxílio do professor com diversas composições. Dentre as metodologias, pode-se fazer um paralelo com uma sala de aula invertida.

A sala de aula invertida é uma metodologia que inverte os papéis tradicionais dos ambientes de ensino e aprendizagem (GROSS; MUSSELMAN, 2018). Com esse sistema, o processo de aquisição de conteúdo e conhecimento passa a ocorrer em casa, com cada aluno ditando o seu próprio ritmo (FERRARINI; SAHEB; TORRES, 2019). Enquanto isso, a sala de aula é um espaço de discussão, dúvidas e atividades intermediada pelo professor (BERGMANN; SAMS, 2018).

Ao utilizar o laboratório virtual como um recurso de uma sala de aula invertida, o aluno pode ter o contato com o conteúdo antes mesmo de conhecer o experimento físico, conseguindo aproveitá-lo de forma mais eficiente e otimizada. Dependendo da forma como o programa é apresentado, boa parte do próprio conteúdo necessário já está disponível permitindo que o 
estudante adquira o conhecimento por si só, retire as dúvidas em sala de aula e visualize o módulo real.

O laboratório virtual, por si só, não se caracteriza como uma metodologia ativa, apesar do uso de recursos digitais e de poder compor uma sala de aula invertida. Como bem discutem Ferrarini, Saheb e Torres (2019), a tecnologia digital é apenas um acessório, um meio para se alcançar o objetivo. Mas são os procedimentos e a configuração das aulas que podem conferir ao aluno o protagonismo no seu processo de aprendizagem. O laboratório virtual é tão somente um meio para dar ao estudante maiores recursos para a obtenção do conhecimento.

\section{Caminhos metodológicos}

Os caminhos metodológicos utilizados neste artigo consistem em três etapas principais. Inicialmente, delinearemos o objeto de estudo indicando sua origem, módulos, linguagem computacional utilizada e seus objetivos. Em seguida, apresentaremos os instrumentos de análise explicando os principais critérios de avaliação ergonômica e pedagógica. Por fim, examinaremos sua possibilidade de aplicação como um recurso didático digital.

\subsection{Objeto de estudo}

Este estudo terá como objeto principal de análise o laboratório virtual LabHidra.com, cujo conceito inicial foi idealizado no departamento de Engenharia Sanitária e Ambiental da Universidade Federal de Santa Catarina frente à necessidade de levar a tecnologia para as disciplinas de hidráulica e adaptar-se à nova realidade dos alunos.

O LabHidra.com é um programa de computador desenvolvido com o objetivo de se tornar um recurso didático integrante de "Hidráulica 1", estudada no curso de Engenharia Sanitária e Ambiental da Universidade Federal de Santa Catarina. O software busca, em sua essência, representar em meio virtual o experimento prático de bombeamento e cavitação, parte da ementa da referida disciplina.

O experimento real (Figura 1) de bombeamento e cavitação tem como objetivo reproduzir circuitos hidráulicos utilizados em instalações prediais contendo equipamentos de bombeamento. Por meio dele, o aluno pode observar diferentes configurações na disposição das bombas e seus efeitos nas pressões de escoamento. Além disso, observar o fenômeno de cavitação em laboratório através do fechamento de uma válvula específica. 
Figura 1 - Experimento físico, modelo para a criação do LabHidra.com.

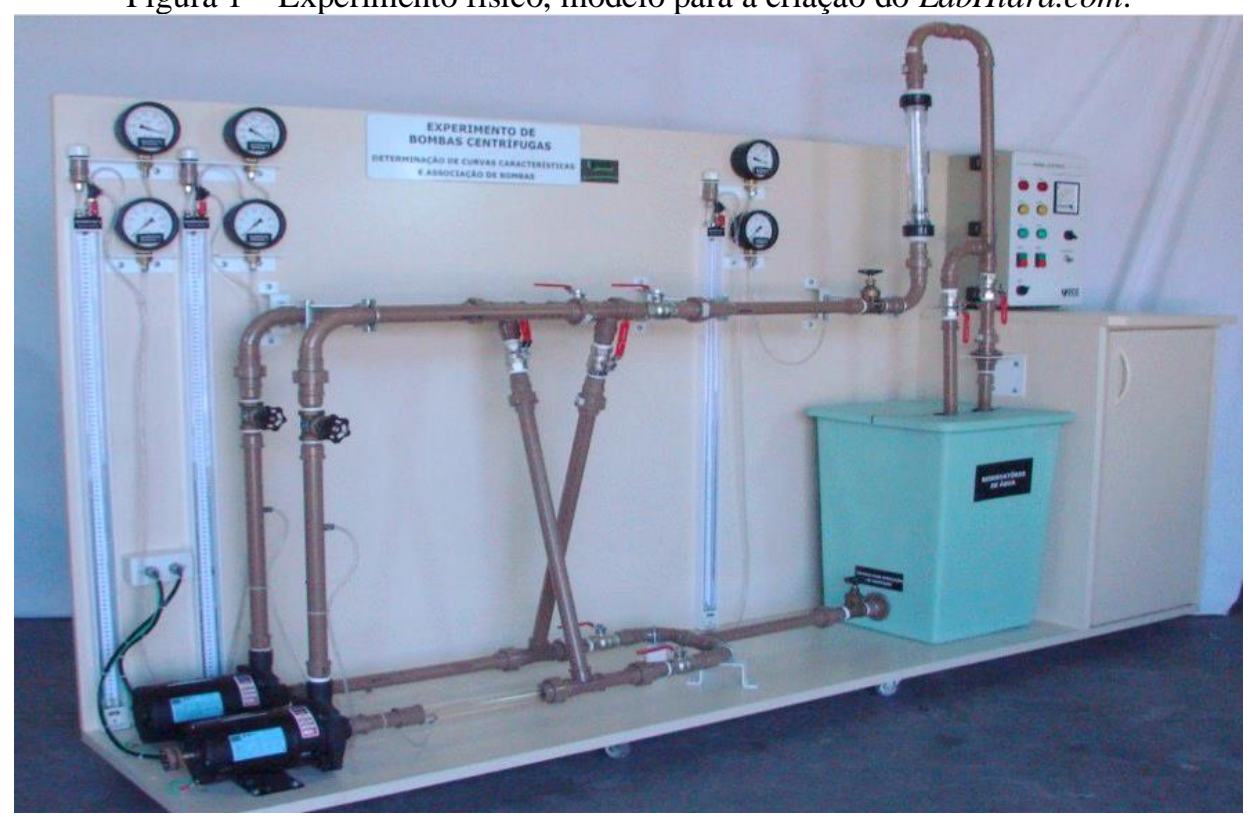

Fonte: Acervo da empresa EcoEducacional (2019).

Sabendo-se que qualquer experimento real tem limitações com relação ao espaço, ao tempo e com questões estruturais, o LabHidra.com buscou, além de reproduzi-lo com fidelidade, ampliar as possibilidades existentes. O programa permite a troca do material da tubulação, a mudança do posicionamento dos acessórios hidráulicos, a alteração do nível do reservatório, a elevação ou redução da temperatura ambiente, dentre outros fatores.

Os experimentos práticos integram uma seção do programa chamada "Módulos", incluindo uma seção para o bombeamento, outra para a cavitação e a terceira para a configuração de circuitos.

Além da parte experimental, o programa apresenta um segmento explicando sobre o próprio funcionamento, seus desenvolvedores, objetivos, apresentação e apoiadores. Há também uma seção onde que há uma imagem interativa do experimento real, destacando cada um dos equipamentos.

A linguagem utilizada para o desenvolvimento do LabHidra.com foi a Visual Basic, utilizando o Visual Studio 2019. Essa linguagem permite uma interface interativa com o usuário com o uso de botões, janelas e imagens. No entanto, possui limitação com relação à construção de gráficos e vídeos, já que o programa normalmente deve ser utilizado off-line.

Vale ressaltar que o objeto de estudo em questão, apesar de ser concebido para ser autossuficiente, não tem como objetivo substituir a prática laboratorial ou mesmo o papel do professor. O experimento virtual visa, acima de tudo, a complementar os conhecimentos existentes preparando melhor o aluno para a experiência e permitindo que adquira informações no seu próprio ritmo.

O programa é uma inovação do Laboratório de Hidráulica da Universidade Federal de Santa Catarina (UFSC) para essa área de ensino. Não existem materiais análogos que trazem a união de um viés pedagógico com a reprodução de experimentos reais com esta temática. 


\subsection{Instrumento de análise}

Para realizar a avaliação do LabHidra.com tivemos como base o instrumento de revisão de objeto de aprendizagem LORI (NESBIT; BELFER; LEACOCK, 2003) e o instrumento de análise de aplicativos Colmeia de Apps (NUNES, 2020). Também nos baseamos em critérios de análise presentes no trabalho de Gadioli et al. (2018).

Foi considerado que o público-alvo do LabHidra.com são alunos, em sua maioria, de quarta ou quinta fase dos cursos de Engenharia Sanitária e Ambiental, de Engenharia Civil e de Engenharia de Produção Civil da Universidade Federal de Santa Catarina. Sobretudo são jovens com provável relação familiar com recursos digitais.

Contemplamos uma análise ergonômica e pedagógica (GADIOLI et al., 2018), com o objetivo de verificar as características gerais do programa em relação à sua estrutura e organização; e também o conteúdo em si, quanto ao potencial de ensino e aprendizagem. Assim, aplicou-se o instrumento Colmeia de Apps (NUNES, 2020), um questionário de análise de recurso didático que, em uma versão adaptada, serviu como base para observar critérios, tais como: dados técnicos; interface gráfica; interatividade; acessibilidade; feedback; e atividades realizadas (adaptadas).

Dessa forma, reunimos no Quadro 1 os critérios adaptados de análise. A análise ergonômica abarcou sobre a interface e aspectos de navegação do programa, enquanto que a pedagógica abordou as metas de aprendizagem e a qualidade do conteúdo.

Quadro 1 - Critérios de análise ergonômica e pedagógica de um OVA.

\begin{tabular}{|c|c|c|}
\hline \multirow[t]{2}{*}{$\begin{array}{l}\text { Análise } \\
\text { Ergonômica }\end{array}$} & Interface gráfica & $\begin{array}{ll}\text { 1. } & \text { Composição da tela } \\
\text { 2. } & \text { Títulos dos menus } \\
\text { 3. } & \text { Distribuição e organização do conteúdo } \\
\text { 4. } & \text { Tipo, cor, tamanho e localização dos ícones } \\
\text { 5. } & \text { Aparência geral }\end{array}$ \\
\hline & $\begin{array}{l}\text { Interatividade, } \\
\text { acessibilidade e } \\
\text { usabilidade }\end{array}$ & $\begin{array}{l}\text { 6. Interação com outros usuários e com redes sociais; } \\
\text { 7. Necessidade de ajuda ao usuário nas atividades e o formato dessa } \\
\text { ajuda; } \\
\text { 8. Se há limite de tempo para a atividade; } \\
\text { 9. Facilidade na navegação; } \\
\text { 10. Feedback: qual o formato, se estimula o aluno, se é de acerto e erro, } \\
\text { se é contextual ou aleatório. }\end{array}$ \\
\hline \multirow[t]{2}{*}{$\begin{array}{l}\text { Análise } \\
\text { Pedagógica }\end{array}$} & $\begin{array}{l}\text { Metas de } \\
\text { aprendizagem }\end{array}$ & $\begin{array}{l}\text { 11. Alinhamento entre as metas de aprendizagem e as atividades e } \\
\text { avaliações propostas; } \\
\text { 12. Clareza dos objetivos; } \\
\text { 13. Atratividade e relevância; } \\
\text { 14. Facilidade de uso; } \\
\text { 15. Capacidade de reutilização em outros contextos de aprendizagem. }\end{array}$ \\
\hline & $\begin{array}{l}\text { Qualidade de } \\
\text { conteúdo }\end{array}$ & $\begin{array}{l}\text { 16. Clareza e coerência de conteúdo; } \\
\text { 17. Precisão e veracidade das informações; } \\
\text { 18. Estruturação do conteúdo; } \\
\text { 19. Equilíbrio na apresentação de ideias; } \\
\text { 20. Nível apropriado de detalhe; } \\
\text { 21. Adequação com público-alvo. }\end{array}$ \\
\hline
\end{tabular}

Fonte: Adaptado de Nesbit, Belfer e Leacock (2003); Nunes (2020); Gadioli et al. (2018).

Vale ressaltar que os critérios da análise ergonômica influenciam direta ou indiretamente no potencial de ensino e aprendizagem do programa, ou seja, na análise 
pedagógica. Esses serão base da investigação do programa e de suas respectivas telas, a serem observados posteriormente.

\subsection{Análise do laboratório virtual como um recurso didático digital}

Nesta etapa, buscou-se avaliar o LabHidra.com como recurso didático digital. Observou-se que o mesmo possui caráter pedagógico e se utiliza a tecnologia e seus recursos midiáticos de forma a melhorar o ensino.

Como forma de aplicação ao ensino, avaliou-se possibilidades de seu uso pelo professor e aluno. Isto é, idealizamos possíveis estratégias de aula pensando como o professor pode incluílo de forma ativa no ensino. Para tal, avaliamos seu uso primeiramente como um recurso de uma sala de aula invertida. Em seguida, verificamos critérios que possam enquadrá-lo ou lhe dar caráter ativo.

\section{Resultados e discussões}

\subsection{Dados gerais do LabHidra.com}

O LabHidra.com é um programa de computador de caráter pedagógico, técnico e experimental. Seu principal objetivo consiste no auxílio à aula experimental de bombeamento e cavitação da disciplina de "Hidráulica 1", complementando o que pode ser visto em laboratório e explicado em aula. Seus dados técnicos constam no Quadro 2.

Quadro 2 - Dados técnicos do recurso didático.

\begin{tabular}{|l|l|}
\hline Nome & LabHidra.com \\
\hline Linguagem & Visual Basic \\
\hline Conexão & Off-line \\
\hline Público-alvo & Alunos de Hidráulica 1 (jovens) \\
\hline Ano & 2019 (registro em 2020) \\
\hline
\end{tabular}

Fonte: Elaborado pelos autores a partir da observação do LabHidra.com (TEIXEIRA, 2019).

O LabHidra.com usou a linguagem Visual Basic, diferindo-se das utilizadas em outros programas relacionados à área de Hidráulica. Chan et al. (2008) usaram a Virtools, uma linguagem de programação visual recomendada para recriar imagens 3D interativas. Já GAO et al. (2011) adotaram a VRML e a Flash que, segundo os autores, são ideais para uma eventual disponibilização online, pois ocupam menos bytes em comparação com a Visual Basic.

O LabHidra.com funciona de forma off-line a partir de um setup que deve ser disponibilizado pelo docente na internet. Dessa forma, o usuário precisa estar conectado a uma rede de ensino para adquirir o programa. $\mathrm{O}$ uso off-line beneficia alunos que não possuem conexão constante ou rápida com a internet, todavia, não permite interatividade entre usuários através do programa. O mesmo ocorre com o laboratório virtual de Gao et al. (2011).

O experimento de Chan et al. (2008) se difere ao disponibilizar o protótipo na internet para uso e atualização contínua pela Virtools. Essa linguagem, segundo os autores, é excepcional para a construção de um ambiente de realidade virtual interativo em tempo real. 


\subsection{Análise das seções do LabHidra.com}

O LabHidra.com é dividido em quatro grandes seções, dispostas em um menu principal (Quadro 3). O usuário pode avançar pelo programa através de botões indicados pelo menu e voltar às telas anteriores por meio de um botão característico.

Quadro 3 - Resumo dos conteúdos das seções do LabHidra.com.

\begin{tabular}{|l|l|}
\hline Seção & Conteúdo \\
\hline Apresentação & $\begin{array}{l}\text { Uma sequência de janelas que explica textualmente o que é o programa, o que será } \\
\text { apresentado e seus objetivos. }\end{array}$ \\
\hline Experimento Real & $\begin{array}{l}\text { Apresenta uma imagem interativa do experimento real a partir da qual o } \\
\text { LabHidra.com foi baseado. Nesta seção, o usuário pode verificar todos os } \\
\text { equipamentos do protótipo através de um clique sobre cada estrutura. Por fim, cita } \\
\text { e agradece à desenvolvedora EcoEducacional. }\end{array}$ \\
\hline Sobre o programa & $\begin{array}{l}\text { Mostra as características gerais do software, incluindo o criador, sua aplicação e os } \\
\text { parâmetros a serem utilizados. }\end{array}$ \\
\hline Módulos & $\begin{array}{l}\text { Maior seção do software. Mostra todos os experimentos virtuais disponíveis, os } \\
\text { formulários necessários e as instruções. }\end{array}$ \\
\hline
\end{tabular}

Fonte: Elaborado pelos autores a partir da observação do LabHidra.com (TEIXEIRA, 2019).

A partir do Quadro 3, podemos notar que o conteúdo segue uma lógica e coerência. Cada seção apresenta sua relevância, porém aquela nomeada de "Módulos" é fundamental, visto que apresenta a interação com os experimentos virtuais.

As telas do programa são padronizadas estética e pedagogicamente. Há padrão no tamanho dos botões, nas cores e na organização dos conteúdos. Podemos observá-las com mais detalhes através da Figura 2, que contém informações das três primeiras seções citadas anteriormente. 
Figura 2 - Telas com informações sobre "Apresentação", "Sobre o Programa" e "Experimento Real".

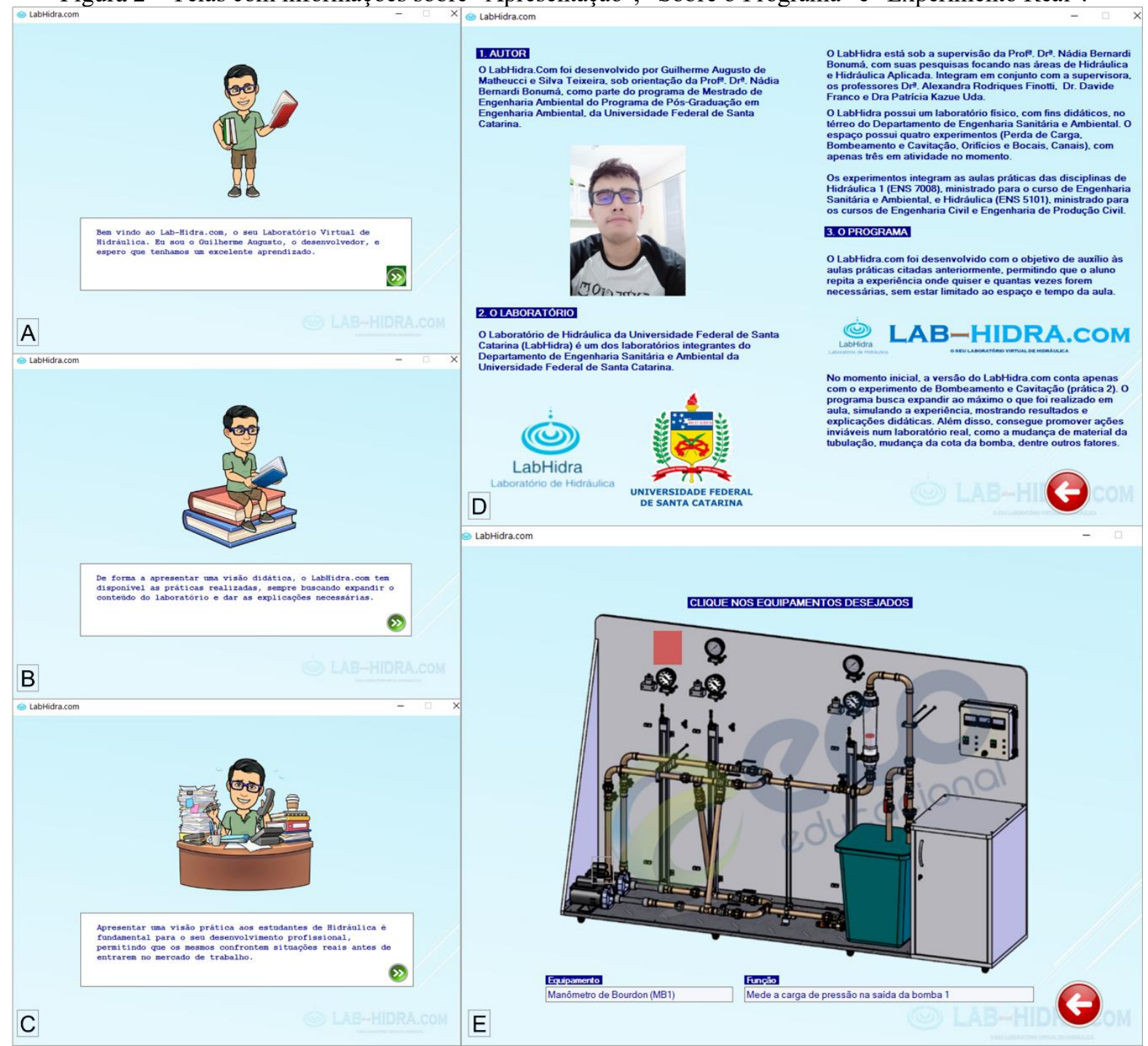

Fonte: Retirado do programa LabHidra.com (TEIXEIRA, 2019).

Legenda: A, B e C: telas de "Apresentação"; D: tela "Sobre o Programa; E: tela "Experimento Real".

Nota-se que não há barra de rolagem em nenhuma das telas do programa e nem possibilidade de redimensionamento. Isto torna-se uma desvantagem em computadores de telas menores (inviabilizando o uso em celulares, por exemplo), pois o estudante tem que mover a janela para observar sua totalidade.

Como destaque, verifica-se que não há um ordenamento entre as seções nem uma sequência didática. Ou seja, o usuário tem total liberdade para navegar da maneira como se sentir mais à vontade. Esse ponto pode ser negativo para alguns, que se sentiriam desorientados sem um guia para navegação. Além disso, os títulos localizados na barra superior da tela são genéricos (LabHidra.com), não indicando em que ponto do programa se está.

No trabalho de Gadioli et al. (2018), um perito da área de informática sugeriu inserir setas para o direcionamento de uma sequência do conteúdo. Em contrapartida, os autores defendem a livre navegação atrelada ao estímulo da criatividade do aluno e da autonomia no aprendizado. Consideramos que o mesmo se aplica ao laboratório virtual do presente estudo. 
De forma geral, sugerimos acrescentar na barra superior o caminho de navegação, e/ou indicar a seção anterior junto à seta inferior de "voltar". Essa indicação pode se dar através de uma mensagem que surge ao passar o mouse sobre o botão. Acreditamos que, deste modo, o aluno poderá se situar melhor dentro do programa, o que auxilia na navegação.

Discutindo sobre as seções, o setor de "Apresentação" tem uma navegabilidade diferenciada. $\mathrm{O}$ aluno pode obter diversas informações sobre o programa de forma sequencial. Ao fundo, há uma trilha sonora que pode motivar seu interesse (Figuras 2.A, 2.B e 2.C).

A seção "Sobre o programa" (Figura 2.D) possui bastante texto e poucas imagens, o que pode causar desinteresse na leitura. Entretanto, apresenta todas as informações necessárias às quais se propôs. Sugerimos repensar o design e a forma de exibição, assemelhando-se à seção de "Apresentação".

De forma geral, as duas seções deixam claro o objetivo de aprendizagem. Indicam que o software serve como auxílio às aulas práticas existentes na disciplina de "Hidráulica 1", complementando o seu conteúdo. Esse objetivo está alinhado com as metas de aprendizagem presentes na disciplina.

A seção de "Experimento Real" (Figura 2.E) apresenta grande interatividade com o usuário, pois esse pode descobrir sobre todos os equipamentos utilizados no experimento. Além disso, auxilia com os termos técnicos usados nos módulos virtuais. A tela é simples, equilibrando imagem e texto. Com relação à sua disposição, sugerimos que fosse incluída como uma subseção de "Módulos" juntamente com os outros experimentos, pois funciona como um reconhecimento prévio do protótipo.

\subsection{Análise dos módulos experimentais do LabHidra.com}

Cada um dos módulos do LabHidra.com busca apresentar um experimento diferenciado, conforme mostra o Quadro 4.

Quadro 4 - Módulos do LabHidra.com.

\begin{tabular}{|l|l|}
\hline Módulo & Conteúdo \\
\hline Bombeamento & $\begin{array}{l}\text { Apresenta o circuito hidráulico no formato de imagem, equivalente ao experimento } \\
\text { real. O aluno, através de três botões no cabeçalho, escolhe se o circuito é } \\
\text { individual, em série ou em paralelo. Através de botões e instruções, pode clicar } \\
\text { para aumentar ou reduzir a vazão, observando o que acontece com as pressões do } \\
\text { escoamento e com a potência disponível pela bomba. A qualquer momento, o } \\
\text { aluno pode modificar o material da tubulação verificando o que acontece com as } \\
\text { pressões. Inclusive, há a possibilidade de simular o experimento realizado em } \\
\text { laboratório. Após observar todas as pressões, pode-se gerar um gráfico } \\
\text { representante da curva característica da bomba e/ou da associação. }\end{array}$ \\
\hline Cavitação & $\begin{array}{l}\text { Apresenta o circuito hidráulico no formato de imagem em corte adaptado do } \\
\text { experimento real. Neste módulo, o aluno verifica as causas da cavitação em um } \\
\text { passo a passo didático. Através de botões, é possível reduzir o nível do } \\
\text { reservatório, elevar a cota da bomba ou fechar a válvula simuladora de cavitação. } \\
\text { Quando a pressão no escoamento for baixa o suficiente, o programa acionará um } \\
\text { alarme indicando a ocorrência de cavitação. }\end{array}$ \\
\hline $\begin{array}{l}\text { Configuração de } \\
\text { circuito (Válvulas) }\end{array}$ & $\begin{array}{l}\text { Apresenta o circuito hidráulico no formato de imagem, equivalente ao experimento } \\
\text { real. Através de botões, o aluno pode clicar para abrir ou fechar determinada } \\
\text { válvula e conferir se o circuito que montou é válido ou não. Se for válido, o } \\
\text { programa indica se é um circuito individual, uma associação em série ou em }\end{array}$ \\
\hline
\end{tabular}




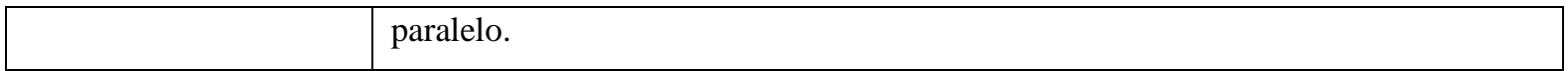

Fonte: Elaborado pelos autores a partir da observação do LabHidra.com (TEIXEIRA, 2019).

Cada módulo apresenta três possibilidades: "Iniciar"; "Instruções"; e "Formulário". O primeiro consiste na realização do experimento virtual em si. Já os outros dois são janelas que explicam, respectivamente, como funciona o módulo e as fórmulas necessárias para os posteriores cálculos.

A seção de "Instruções" apresenta um formato de ajuda dissociado do experimento. Se o aluno, porventura, não souber o próximo passo a ser realizado, tem que deixar a janela em que está e voltar para essa aba. Isso prejudica a navegabilidade e, por consequência, a imersão no conteúdo em si. A existência de uma aba somente com os procedimentos também está presente no laboratório virtual de hidráulica de Gao et al. (2011).

Tanto na seção de "Instruções" quanto na de "Formulário" os elementos estão dispostos essencialmente em forma textual, com poucas imagens. Se, por um lado, apresenta-se todo o conteúdo em uma única tela, por outro, há um excesso de informações. Dessa forma, se assemelha muito mais a um manual de instruções, não se aproveitando do potencial que um recurso didático pode oferecer.

\section{a) Módulo de bombeamento}

Ao observar a tela principal do Módulo de bombeamento (Figura 3), percebe-se que há um excesso de componentes visuais e textuais, a maioria sem interação. Esse exagero acaba dificultando ao aluno a percepção de onde começa o experimento. As instruções existentes se perdem em meio às imagens e textos, além de não apresentarem cores diferenciadas.

Comparando a tela principal com a de outro laboratório virtual de hidráulica (GAO et al., 2011), há uma quantidade ainda mais excessiva de informações visuais e textuais. Ademais, os equipamentos são mostrados de forma muito detalhada e técnica prejudicando a visualização de um todo. 
Figura 3 - Telas do módulo com o experimento virtual de "Bombeamento".

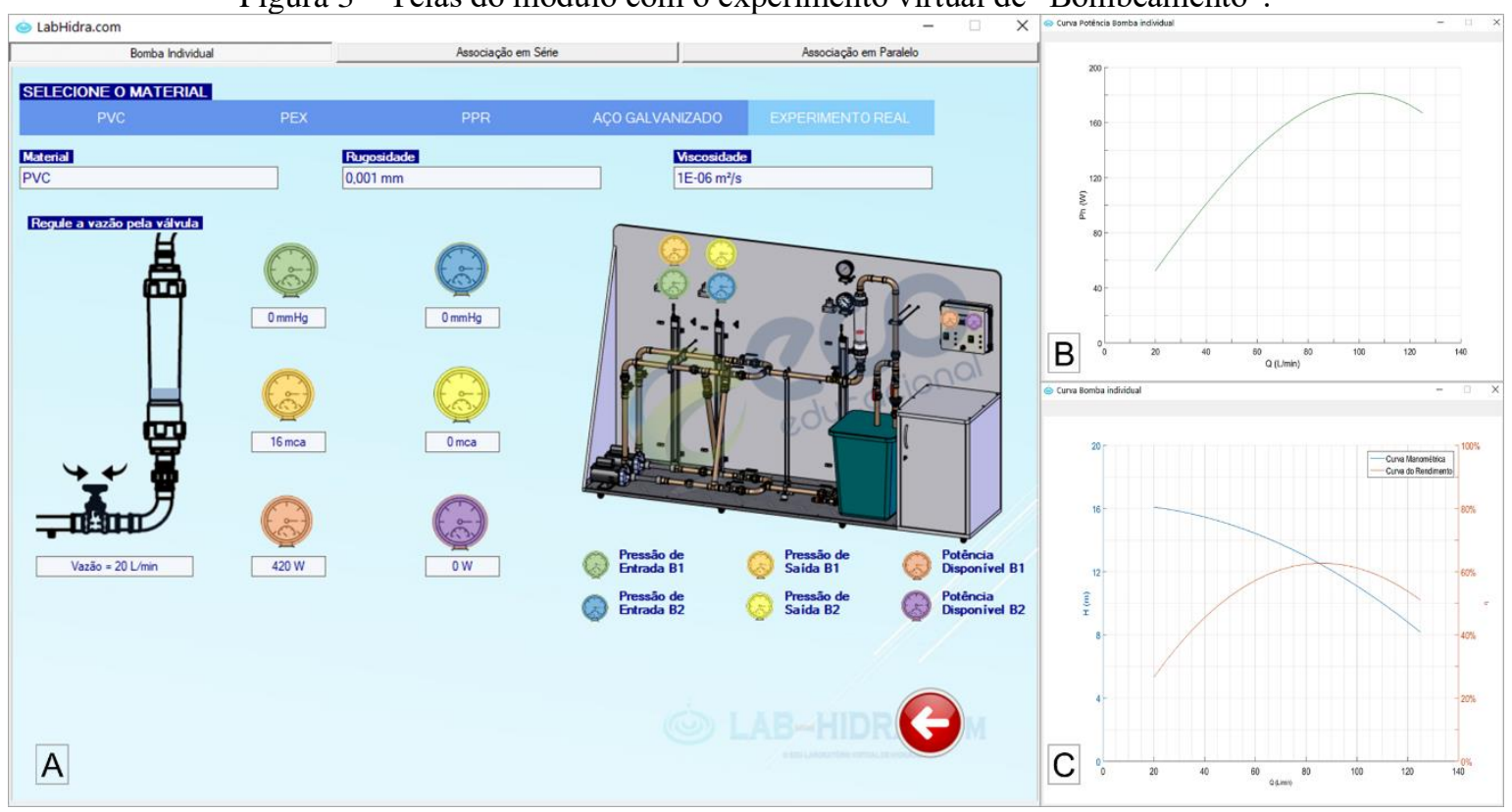

Fonte: Retirado do programa LabHidra.com (TEIXEIRA, 2019).

Legenda: A: tela inicial do módulo; B e C: gráficos gerados ao final do experimento.

Inicialmente, parece haver baixa interatividade com os elementos da tela do módulo de bombeamento. Mas à medida que se explora, percebe-se que há, de fato, uma interatividade: é possível alterar o material da tubulação (o que modifica as pressões e potências) e a configuração do circuito (barra superior). Sugerimos que, para melhorar a interface e a interatividade, os elementos apareçam conforme o aluno for realizando o experimento. As mudanças nos componentes também estão presentes nos laboratórios virtuais de Chan et al. (2008) e em Gao et al. (2011).

Apesar do excesso de informações, há um equilíbrio homogêneo de cores sem causar poluição visual e predominando tons de azul. Isso se difere do laboratório virtual de Gao et al. (2011), que apresenta uma heterogeneidade na utilização das cores.

Com relação aos relógios de medição do LabHidra.com, suas cores se destacam do fundo. Entretanto, a semelhança entre alguns, inclusive no formato, pode dificultar a identificação.

Os gráficos finais (Figuras 3.B e 3.C) são apresentados em forma de imagem no programa como um feedback. No entanto, se o aluno quiser reproduzi-lo precisa fazer externamente, seja através de outro programa (Excel, por exemplo) ou à mão. Como o software não recebe informações externas, há um comprometimento com relação à interatividade. Além disso, se o usuário não acessou a aba "Instruções" previamente pode chegar ao final sem ter realizado os cálculos necessários, dificultando o aprendizado. Ressaltamos a importância de uma instrução mais clara e na própria tela, indicando o passo a passo e o objetivo final.

No trabalho de Gao et al. (2011), o feedback também é dado através de um gráfico. Entretanto, não se trata de uma imagem estática, possuindo elementos que se alteram conforme a manipulação dos dados. Assim, nota-se uma desvantagem do LabHidra.com, que perde um pouco seu caráter dinâmico e interativo nesta função. 
No experimento virtual de Chan et al. (2008) o feedback é fornecido em forma de avisos de erro que impedem o usuário de prosseguir, em caso de não completarem as solicitações do sistema.

b) Módulo de cavitação

Diferentemente do módulo de bombeamento, há uma quantidade significativamente menor de elementos na tela inicial do módulo de cavitação. Conforme vão sendo realizados os passos, novos elementos interativos surgem na tela em uma sequência didática lógica (Figura 4). Dessa forma, há maior facilidade em entender a dinâmica do experimento.

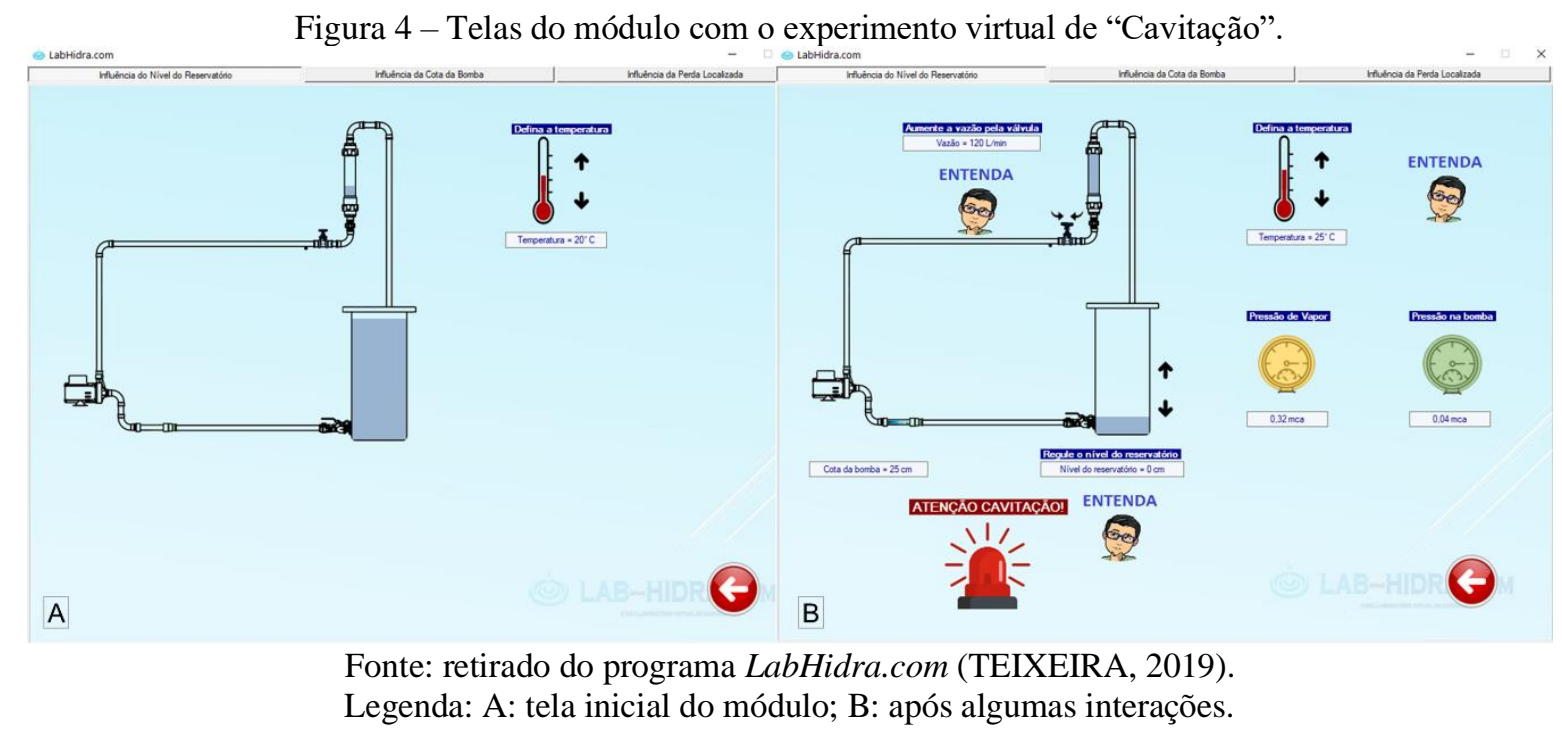

As cores utilizadas seguem um equilíbrio, como no módulo de bombeamento. Alguns elementos se movem de acordo com as ações realizadas, contribuindo para a interatividade. A manipulação dos equipamentos e a movimentação dos componentes na figura ocorrem também nos laboratórios virtuais de Chan et al. (2008) e de Gao et al. (2011).

O feedback é dado na forma de alarme com imagem, texto e som indicando que as condições para a ocorrência do fenômeno de cavitação foram atendidas. Destaca-se a utilização do vermelho para chamar a atenção do usuário.

c) Módulo de válvulas

O módulo de válvulas difere-se dos outros dois, pois há apenas uma tela com poucos elementos visuais (Figura 5). Sua composição é equilibrada com uma imagem, botões e poucos textos. Dessa forma, facilita-se a observação das instruções. O uso das cores não compromete a visualização dos elementos. Além disso, há o uso de letras "A" e "F" para auxiliar na identificação do estado das válvulas. 


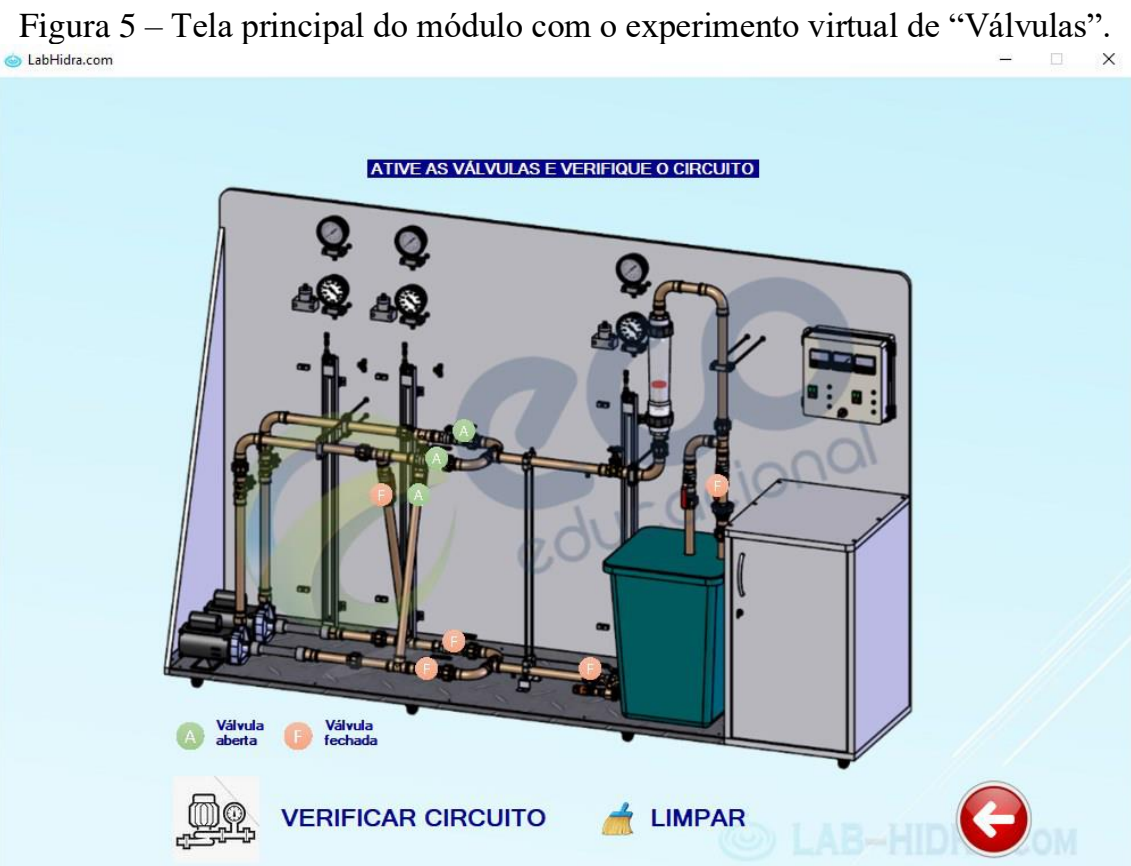

Fonte: Retirado do programa LabHidra.com (TEIXEIRA, 2019).

O módulo apresenta ilustração com noções de 3D, assim como os experimentos de Chan et al. (2008) e de Gao et al. (2011). Essa mescla das visões 3D e 2D em um modelo de visualização é considerada um ponto positivo na aprendizagem, pois há o complemento de uma em relação a outra.

O feedback da atividade pode ser gerado através do botão "Verificar Circuito", que apresenta uma combinação de imagem e texto facilitando o entendimento de sua funcionalidade. O resultado é dado de forma textual, sonora e através de símbolos que se diferem, caso o aluno responda de forma correta ou incorreta. Isso não é considerado nem estimulante nem o contrário, pois somente mostra se o usuário acertou ou não.

Nessa seção, não há uma autossuficiência de conteúdo, pois o aluno precisa ter um conhecimento prévio de configuração de circuitos para poder realizar a atividade de forma consciente, sem ser apenas por tentativa e erro.

d) Ferramenta de ajuda

O programa possui um recurso de ajuda interativo em relação ao conteúdo teórico apresentado, e surge na forma de um botão com uma imagem e texto com a palavra "Entenda" (Figura 6).

Figura 6 - Ícone da ferramenta de ajuda, disponível nos módulos experimentais.

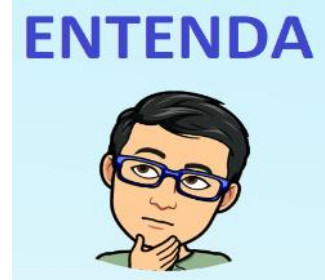

Fonte: Retirado do programa LabHidra.com (TEIXEIRA, 2019). 
Esse botão aparece conforme o aluno realiza as ações do experimento, surge em local e tamanho visíveis para ser acessado com facilidade. Ao fechar a janela, o botão sumirá da tela, o que evita uma poluição visual.

A ajuda surge em uma janela à parte e se inicia através de uma pergunta, que é respondida à medida que o aluno for avançando nas setas para mais telas com explicações. Esse recurso se dá nos formatos de texto, imagem, esquemas e fórmulas para a consolidação do conteúdo, como ilustrado na Figura 7.

Figura 7 - Telas de ajuda com destaque para imagem, texto, fórmulas e modo de navegação.

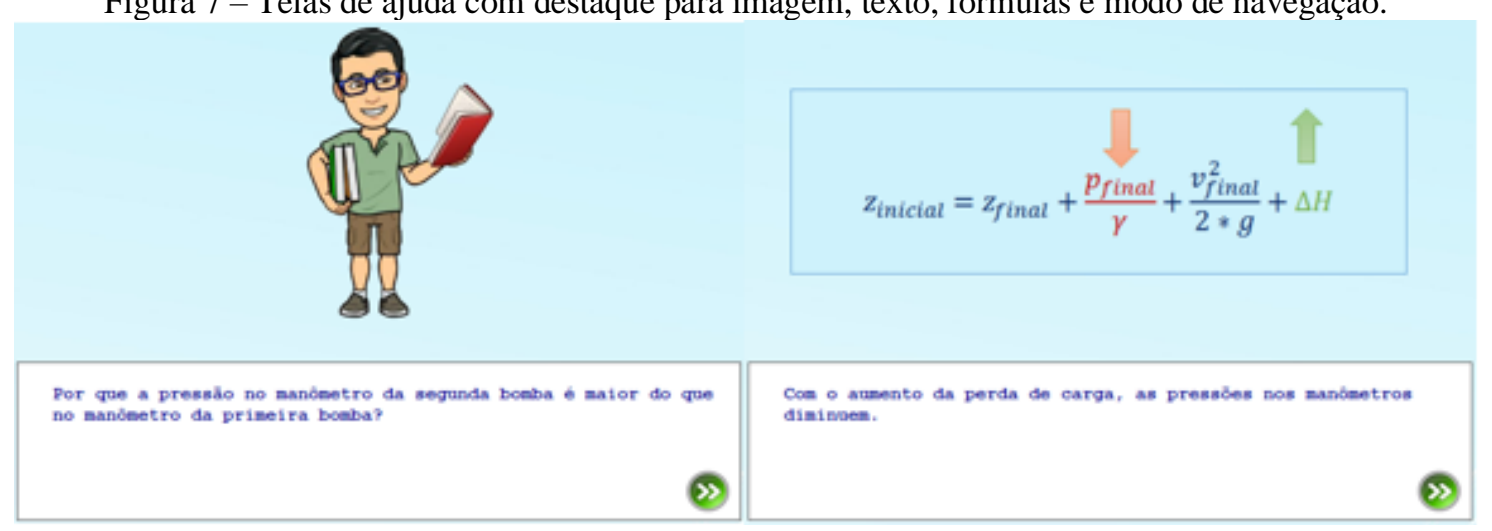

Fonte: Retirado do programa LabHidra.com (TEIXEIRA, 2019).

Consideramos tal recurso como um dos principais elementos para tornar o programa mais didático e atingir sua função pedagógica dentro do contexto da disciplina. Essas explicações são importantes para garantir a compreensão do experimento. Para os usuários que já sabem o conteúdo, é uma forma de revisão, e para quem possui dificuldades é de grande valia. Isso possibilita que alunos de diferentes níveis de aprendizado na disciplina atinjam o mesmo objetivo didático. Esse formato de ajuda é o principal diferencial em relação aos outros laboratórios virtuais existentes na área de hidráulica (CHAN et al., 2008; GAO et al., 2011).

Além disso, é uma ferramenta atrativa e que motiva o aluno a continuar o experimento, mais consciente de todo o processo.

5.4 Análise do LabHidra.com como recurso didático digital e suas possibilidades de aplicação

O LabHidra.com pode ser entendido como um recurso didático digital concebido para fins de ensino e aprendizagem. Suas formas de desenvolvimento, conteúdo e interface lhe dão um caráter claramente pedagógico.

Com a proposta de ser utilizado em casa pelo aluno, de forma off-line, o recurso computacional não pode ser atualizado de forma constante. A princípio, podemos pensar que não intensifica a relação entre os participantes do processo educacional, pois o programa não é complementado ou modificado por outros usuários ao longo do tempo. Entretanto, ainda assim é capaz de tornar a interação entre aluno e professor mais proveitosa no momento da sala de aula.

Conforme discute Machado (2017), o recurso didático digital deve apoiar o desenvolvimento das aulas, e não o substituir. Aqui, o programa atende bem essas necessidades, 
pois serve como um complemento aos experimentos práticos realizados em laboratório. Nesse contexto, percebemos que é possível também reutilizar o LabHidra.com para o ensinoaprendizagem desse experimento virtual em outros contextos de disciplinas relacionadas à hidráulica, o que o caracteriza como um OVA.

O LabHidra.com, por si só, é apenas um programa de computador didático com uma gama de conteúdos inserida. Suas diferentes formas de aplicação, no entanto, são o cerne para avaliar sua viabilidade ou não como uma metodologia ativa de ensino.

Existem duas propostas básicas de aplicação do objeto: depois ou antes do experimento real. No primeiro caso, o instrumento computacional seria empregado mais com um viés de revisão e aprofundamento, o que também poderia suscitar questionamentos que não surgiriam no experimento real devido à maior amplitude de possibilidades. A interação entre professor $\mathrm{e}$ aluno seria, portanto, intensificada após o uso e a aquisição de mais conhecimentos com o programa. Aqui, a metodologia empregada não seria ativa, pois o conteúdo principal é dado em sala e o aluno só revisaria e aprimoraria seu aprendizado em casa.

A segunda aplicação é uma proposta de ter um primeiro contato com o experimento virtualmente, a agir de forma introdutória e explicativa. O uso anterior do programa induz uma aprendizagem prévia podendo munir o aluno de mais argumentos, perguntas e maior senso crítico de todo o procedimento experimental quando observado no modo real. Dessa forma, a troca de informações pode ser otimizada entre os envolvidos durante uma discussão presencial.

Como apresenta boa autossuficiência na relação dos conteúdos, o estudante pode adquirir previamente o conhecimento, repetir o experimento quantas vezes achar necessário e no seu próprio ritmo. A sala de aula (no caso, o laboratório real) serviria para concretizar o que foi visualizado e para tirar as dúvidas. Essa forma de aprendizagem se assemelha a uma sala de aula invertida, diversificando os recursos didáticos disponíveis. Gao et al. (2011), inclusive, utilizaram o seu software dessa forma, aplicando-o antes da realização de um experimento real.

Por permitir que cada aluno aprenda sozinho em casa sem limitação de espaço e tempo, há aqui um caráter ativo de aprendizagem. A personalização do ensino propiciada pelo LabHidra.com, ainda que limitada, pode encorajar a construção do conhecimento de cada um. De acordo com Ferrarini, Saheb e Torres (2019), como o conteúdo é produzido pelo professor e o aluno está restrito ao programa pode haver uma passividade na busca de novas informações.

Em resumo, o programa é um bom recurso didático digital de apoio que altera as metodologias e as dinâmicas de ensino. Vale para pensar na utilização de mais elementos em sala de aula de forma a engrandecer o papel ativo e protagonista do aluno.

\section{Considerações finais}

O LabHidra.com é um recurso didático utilizado de forma pontual no currículo da disciplina de "Hidráulica 1". Pode ser considerado uma pequena peça de um todo, mas também como uma engrenagem importante que movimenta o uso das tecnologias digitais como uma nova realidade potencializadora na educação.

A linguagem apresentada no programa pode ser considerada hipermidiática, integrando diferentes tipos de recursos possíveis, como áudio, imagem, texto, botões e gráficos. $\mathrm{O}$ estudante, em diversos momentos, tem ajudas didáticas com figuras específicas que surgem para auxiliar na compreensão do conteúdo e intensificando a interatividade. Em suma, pode ser usado de diversas formas pedagógicas, o que caracteriza um OVA. 
Possui uma multifuncionalidade ao despertar e motivar o aluno, desenvolver suas capacidades e ilustrar os conteúdos. Sobretudo, aproxima o estudante da realidade com a representação de um experimento prático, essencial para a sua formação. Desse modo, é um instrumento potencializador do ensino e aprendizagem com características propícias para aumentar a motivação daquele.

Com o laboratório virtual, o aluno pode ter a autonomia de utilizar esse recurso em casa seguindo seu ritmo, como uma sala de aula invertida, obtendo o protagonismo. No entanto, vale ressaltar a importância da prática real e da sala de aula para promover a visualização concreta dos experimentos. Ademais, isso permitirá o diálogo com o professor que mediará o aprendizado e promoverá discussões, e com os outros alunos, construindo um conhecimento em conjunto.

\section{Referências}

BACICH, L.; MORAN, J. (org.). Metodologias ativas para uma educação inovadora: uma abordagem teórico-prática. 1. ed. Porto Alegre: Penso, 2018.

BERBEL, N. A. N. As metodologias ativas e a promoção da autonomia de estudantes. Semina: Ciências sociais e humanas, v. 32, n. 1, p. 25-40, 2011.

BERGMANN, J.; SAMS, A. Sala de aula invertida: uma metodologia ativa de aprendizagem. Rio de Janeiro: LTC, 2018.

BORGES, F. F.; TEIXEIRA, J. A.; ACEDO, S. O. Uso de repositórios de recursos educacionais abertos nas práticas pedagógicas: uma revisão sistemática. Relatec Revista Latinoamericana de Tecnología Educativa, [s.l.], v. 19, n. 2, p. 115-113, 2020. Disponível em: https://relatec.unex.es/article/view/3802. Acesso em: 01 fev. 2021.

BORGES, T. S.; ALENCAR, G. Metodologias ativas na promoção da formação crítica do estudante: o uso das metodologias ativas como recurso didático na formação crítica do estudante do ensino superior. Cairu em revista, v. 3, n. 4, p. 119-143, 2014.

CHAN, Y. et al. Development of virtual equipment for a hydraulic mechanics experiment. Tsinghua science and technology, v. 13, p. 261-265, 2008.

DE SOUZA, S. E.; DE GODOY DALCOLLE, G. A. V. O uso de recursos didáticos no ensino escolar. Arq Mudi, Maringá, v. 11, n. 2, p. 110-114, 2007.

DOS SANTOS, A. C.; NICOLETE, P. C.; SILVA, J. B. Ensino Híbrido: Relato de Experiência sobre o uso de AVEA em uma proposta de Sala de Aula Invertida para o Ensino Médio. RENOTE, v. 15, n. 2, 2017.

DOS SANTOS, C. P.; SOARES, S. R. Aprendizagem e relação professor-aluno na universidade: duas faces da mesma moeda. Estudos em Avaliação Educacional, [s.l.], v. 22, n. 49, p. 353, 30 ago. 2011. Disponível em: http://dx.doi.org/10.18222/eae224920111980. Acesso em: 01 fev. 2021. 
ECOEDUCACIONAL. Bancada de Bombas Centrífugas. 2019. Disponível em: https://www.ecoeducacional.com.br/product-page/bancada-de-bombas-centr\%C3\%ADfugas. Acesso em: 30 ago. 2019.

EITERER, C. L.; MEDEIROS, Z. Recursos Pedagógicos. 2010. Disponível em: https://gestrado.net.br/verbetes/recursos-pedag-gicos/. Acesso em: 01 fev. 2021.

FERRARINI, R.; SAHEB, D.; TORRES, P. L. Metodologias ativas e tecnologias digitais. Revista Educação em Questão, [s.l.], v. 57, n. 52, p. 1-30, 18 mar. 2019. Disponível em: https://periodicos.ufrn.br/educacaoemquestao/article/view/15762. Acesso em: 01 fev. 2021.

GADIOLI, B. et al. Construção e validação de um Objeto Virtual de Aprendizagem para o ensino da semiologia vascular venosa periférica. Escola Anna Nery, v. 22, n. 4, 2018.

GALLO, P.; PINTO, M. G. Professor, esse é o objeto virtual de aprendizagem. Revista Tecnologias na Educação, v. 2, n. 1, p. 1-12, 2010.

GAO, Z. et al. Virtual hydraulic experiments in courseware: 2D virtual circuits and 3D virtual equipments. Computer Applications in Engineering Education, [s.l.], v. 19, n. 2, p. 315326, 21 abr. 2011. Disponível em: http://dx.doi.org/10.1002/cae.20313. Acesso em: 30 ago. 2019.

GROSS, S. P.; MUSSELMAN, E. S. Implementation of an Inverted Classroom in Structural Design Courses. Journal Of Professional Issues In Engineering Education And Practice, [s.l.], v. 144, n. 3, jul. 2018. Disponível em: http://dx.doi.org/10.1061/(asce)ei.19435541.0000362. Acesso em: 30 ago. 2019.

HODGE, H.; HINTON, H. S.; LIGHTNER, M. Virtual Circuit Laboratory. Journal Of Engineering Education, [s.l.], v. 90, n. 4, p. 507-511, out. 2001. Disponível em: http://dx.doi.org/10.1002/j.2168-9830.2001.tb00632.x. Acesso em: 30 ago. 2019.

KANG, S. et al. Development of Virtual Equipment: Case Study of the Venturi Tube Experiment. Journal Of Professional Issues In Engineering Education And Practice, [s.l.], v. 139, n. 4, p. 281-289, out. 2013. Disponível em: http://dx.doi.org/10.1061/(asce)ei.1943-5541.0000158. Acesso em: 30 ago. 2019.

LEUNG, M.; WANG, Y.; CHAN, D. K. K. Structural Surface-Achieving Model in the Teaching and Learning Process for Construction Engineering Students. Journal Of Professional Issues In Engineering Education And Practice, [s.l.], v. 133, n. 4, p. 327-339, out. 2007. Disponível em: http://dx.doi.org/10.1061/(asce)1052-3928(2007)133:4(327). Acesso em: 30 ago. 2019.

MACHADO, M. F. R. C. O uso dos recursos didático-tecnológicos como potencializadores ao processo de ensino e aprendizagem. In: CONGRESSO NACIONAL DE EDUCAÇÃO, 4 ., 2017, Curitiba. Anais [...]. Curitiba, 2017. p. 1-11.

MITRE, S. M. et al. Metodologias ativas de ensino-aprendizagem na formação profissional em saúde: debates atuais. Ciência \& Saúde Coletiva, [s.l.], v. 13, n. 2, p. 2133-2144, dez. 2008. Disponível em: http://dx.doi.org/10.1590/s1413-81232008000900018. Acesso em: 01 fev. 2021. 
NEDIC, Z.; MACHOTKA, J.; NAFALSKI, A. Remote laboratories versus virtual and real laboratories. IEEE, 2003.

NESBIT, J. C.; BELFER, K.; LEACOCK, T. Learning object review instrument (LORI). E-learning research and assessment network, 2003.

NEUPAUER, R. M.; DENNIS, N. D. Classroom Activities to Illustrate Concepts of Darcy's Law and Hydraulic Conductivity. Journal Of Professional Issues In Engineering Education And Practice, [s.l.], v. 136, n. 1, p.17-23, jan. 2010. Disponível em: http://dx.doi.org/10.1061/(asce)1052-3928(2010)136:1(17). Acesso em: 30 ago. 2019

NUNES, G. M. Colmeia de Apps: Desenvolvimento e aprimoramento de uma plataforma digital e colaborativa de análise de aplicativos de línguas estrangeiras. $2020.103 \mathrm{f}$. Dissertação (Mestrado) - Curso de Educação, Programa de Pós-Graduação em Educação, Universidade Federal de Santa Catarina, Florianópolis, 2020.

SALVADOR, P. T. C. O. et al. Virtual learning object and environment: a concept analysis. Revista Brasileira de Enfermagem, [s.l.], v. 70, n. 3, p. 572-579, jun. 2017. Disponível em: http://dx.doi.org/10.1590/0034-7167-2016-0123. Acesso em: 01 fev. 2021.

TEIXEIRA, G. A. M. S. LabHidra.com. Versão 1.1 [s.l.], 2019, 1 CD.

YARBROUGH, S. E.; GILBERT, R. B. Development, Implementation, and Preliminary Assessment of Virtual Laboratory. Journal of Professional Issues in Engineering Education and Practice, [s.l.], v. 125, n. 4, p.147-151, out. 1999. Disponível em: 10.1061/(asce)1052-3928(1999)125:4(147). Acesso em: 30 ago. 2019.

Recebido em agosto de 2021.

Aprovado em outubro de 2021. 